\title{
EXPERIMENTAL STUDY OF THE FORCES ABOVE AND UNDER THE VIBRATION INSULATORS OF DIESEL GENERATOR IN TRANSITIONAL REGIMES
}

\author{
Valyo Nikolov ${ }^{1}$, Krasimir Ambarev ${ }^{2}$ \\ ${ }^{I}$ Associate Professor, PhD, Department of Transport and Aviation Equipment and Technologies, \\ Technical University of Sofia, branch Plovdiv, Bulgaria \\ ${ }^{2}$ Assistant Professor, Department of Transport and Aviation Equipment and Technologies, \\ Technical University of Sofia, branch Plovdiv, Bulgaria
}

\begin{abstract}
This paper presents an established measuring system of the forces above and under the vibration insulators of the unit with a fourcylinder diesel engine and electric generator. Here are presented the components of the measurement system and the methodology created for measurements of bearings reactions above and under the elastic suspension elements of the unit, in a vertical direction, in which the data for the measured value is stored, processed and visualized in a MATLAB environment. The results that were obtained from the measurements of the forces above and under the four vibration insulators of the diesel generator are analyzed and graphically presented in this paper, as a function of the time at the transitional modes: starting, stopping, uploading and downloading with electrical load. The results that were obtained from measurements of the forces above and under the four vibration insulators of the diesel generator and per one working cycle of the diesel engine are presented and analyzed in this paper, as a function of the angle of rotation of the crankshaft at full load (maximum electrical load) and at idle running (without electrical load). With the thus created measurement system and methodology, scientific and applied researches can be conducted, in order to determine the quality of the vibration insulation of machine units with internal combustion engines.
\end{abstract}

Keywords: Internal combustion engines, diesel generator, measuring, experimental study.

\section{INTRODUCTION}

The operation of the internal combustion engine is accompanied by the action of various forces and moments created by them, which periodically change their magnitude and direction. The unbalanced forces and moments created during the operation of the internal combustion engine, generate variable in size and direction components at the points of attachment of its body. In the case of a joint work of internal combustion engine and electric generator, a vibration insulators are mounted on the supports of their bodies, designed to reduce the amplitudes of the forces acting on the base of the unit.

The purpose of this work is the study of the forces above and under the vibration insulators on a unit with single-cylinder four-stroke diesel engine and electric generator in transitional modes - starting, loading, unloading and stopping, whereat the data for the measured values has to be stored, processed and visualized in an environment of MATLAB.

\section{EXPERIMENTAL SYSTEM}

The experimental system is developed on the grounds of a diesel unit for alternating current made by "KIPOR" (China) "KDE 6500T" model [7].

The unit is designed for the production of single-phase alternating current, whereat the diesel engine directly drives the AC generator. A constant speed of the diesel engine rotation $-\mathrm{n}=3000 \mathrm{~min}^{-1}$, is maintained by a mechanical regulator, which provides constant frequency of the generated voltage $-\mathrm{f}=50 \mathrm{~Hz}$. 


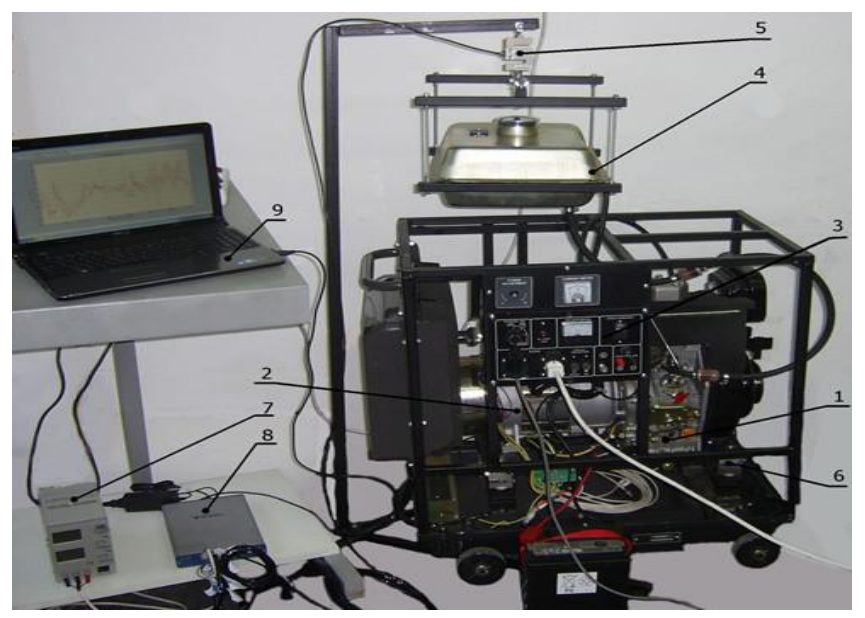

Fig -1: General view of the experimental measurement system: 1 - diesel engine; 2 - generator; 3 - control panel; 4 fuel tank; 5 and 6 - strain transducer; 7 - power supply; 8 analog-to-digital converter; 9 - computer.

The maintenance of a constant output voltage of the generator at different values of the electrical load is carried out with an automatic voltage regulator built into the unit.

The initial start of the diesel engine is carried out by starting electric motor (starter), powered by a rechargeable battery.

The main characteristics of the generator, the diesel engine and the automatic voltage regulator are presented in [7].

The outer casing with damper materials and the side wall on the side of the diesel engine are removed from the electric diesel unit [1]. A construction is made from welded square profiles - Fig. 1, which is attached to the control panel of the experimental measurement system.

In order to load the diesel engine to the AC output of the generator, an electric load is connected that consists of 7 electric heaters with a single nominal power $650 \mathrm{~W}$. The regulation of the electrical load is carried by a potentiometer on the control panel.

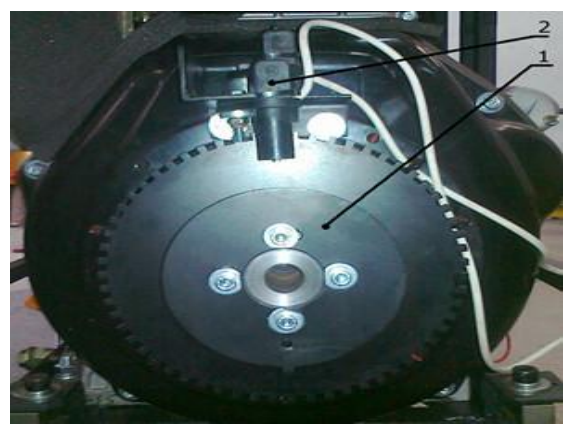

Fig -2: Location of the induction sensor for TDC 1 - one cog wheel; 2 - induction sensor.
The operation of the system requires a signal to an top dead center (TDC) of the piston of the engine $[2, \ldots, 6]$. This signal is generated by an inductive sensor, operated with one cog wheel. The wheel is mounted to the free end of the crankshaft of the engine (fig. 2). The main technical data for the induction sensor is presented in [9].

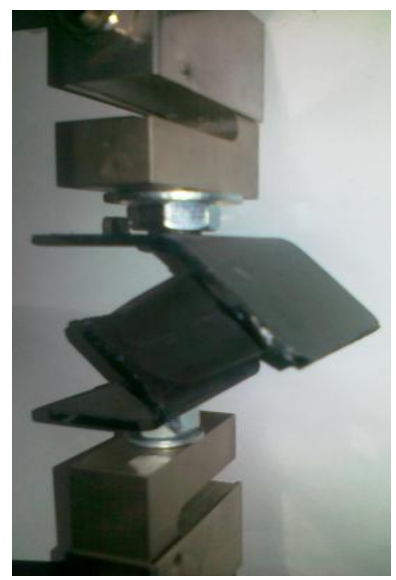

Fig -3: Location of the strain transducers during measurement of forces at the front left of the unit support

The measurement of the reactions in the supports above and under the four vibration insulators is performed by strain transducers 8 (Fig. 3).

The main technical data of the used strain transducers is given in [11].

The conversion of the analog measurement signal into digital is performed by the analog-to-digital converter of the company "National Instruments" - USB-6343. Its main technical data is presented in [10].

During the Measurements 8 of the analog inputs of the analogto-digital converter are used, to which the outputs of the strain transducers are differentially connected.

The recording of the measurements of forces is carried out through a program in MATLAB environment, using the "Data Acquisition Toolbox" [8]. The Measurement data are stored in a file with "mat" extension, allowing their further use, processing and visualization.

\section{METHODOLOGY FOR MEASUREMENT OF THE FORCES}

The measurement of the forces above and under the unit is performed according the following methodical steps:

1. Starting with the measurement program - assigning of the variable values for the strain transducer supply voltage, the outputs at full load for each strain transducer, the number of 
measurements per second, and for the duration of the measurement

2. Initial measurement of voltage outputs of strain transducers for each support for a short period of time - $1 \mathrm{~s}$, at idle engine and immobile work station.

3. Automatic software reset of the strain transducer readings.

4. Starting the diesel engine

5. Recording of the measurements

6. Transformation of the measured values of voltage into force values in the various channels at the location of the sensors.

7. Conversion of time in angle of rotation of the crankshaft

8. TDC synchronization by means of the measured values of the inductive sensor

9. Visualization of the results from the measurements of the forces above and under the four vibration insulators of the diesel generator

\section{RESULTS FROM THE MEASUREMENT OF the FORCES}

With the experimental measurement system are performed measurements of the forces above and under the four vibration insulators of the diesel generator under transitional operating modes - starting, stopping, loading and unloading.

The results of the measurements of the forces above and under the four vibration insulators of the diesel generator when running are presented graphically in Chart 1, 2, 3 and 4.

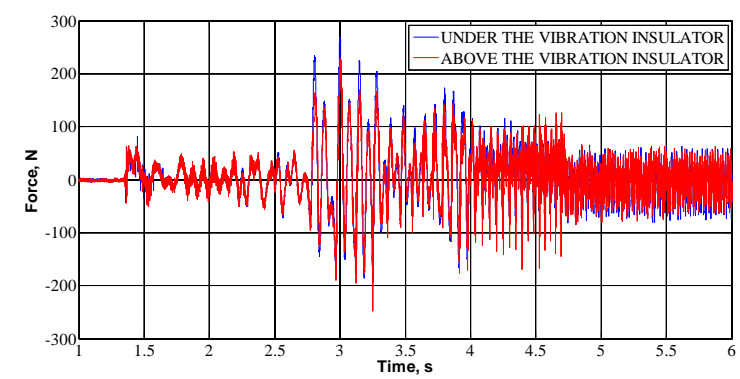

Chart -1: Forces above and under front left vibration insulator at starting of the diesel generator

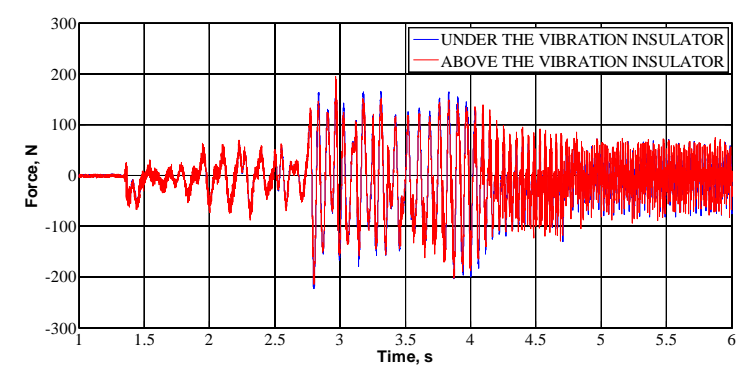

Chart -2: Forces above and under front right vibration insulator at starting of the diesel generator

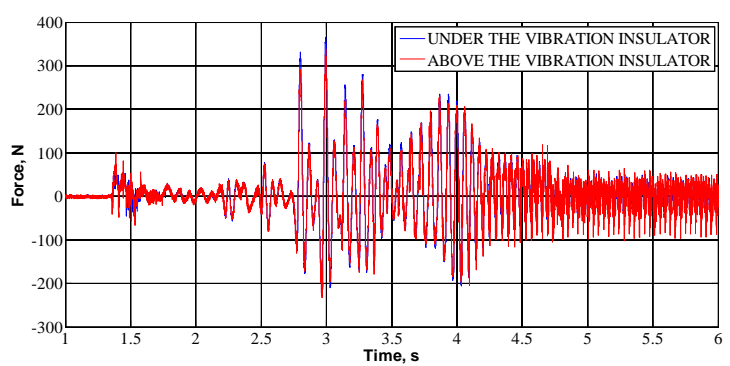

Chart -3: Forces above and under rear left vibration insulator at starting of the diesel generator

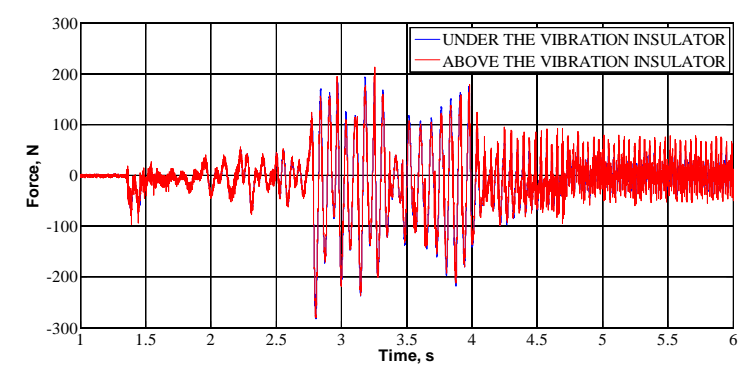

Chart -4: Forces above and under rear right vibration insulator at starting of the diesel generator

The results of the measurements of the forces above and under the four vibration insulators of the diesel unit at stopping, are presented graphically in Chart 5, 6, 7 and 8 .

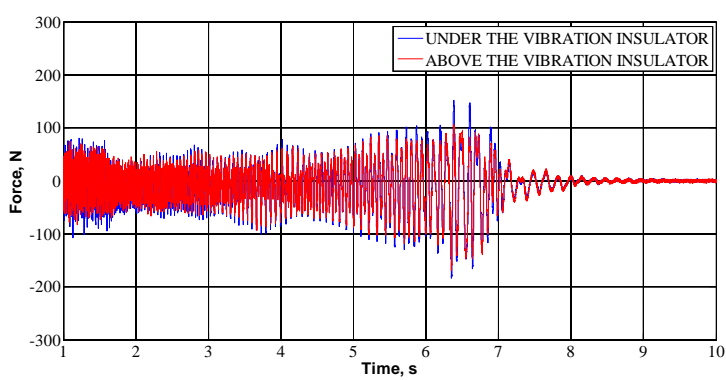

Chart -5: Forces above and under front left vibration insulator at stopping of the diesel generator

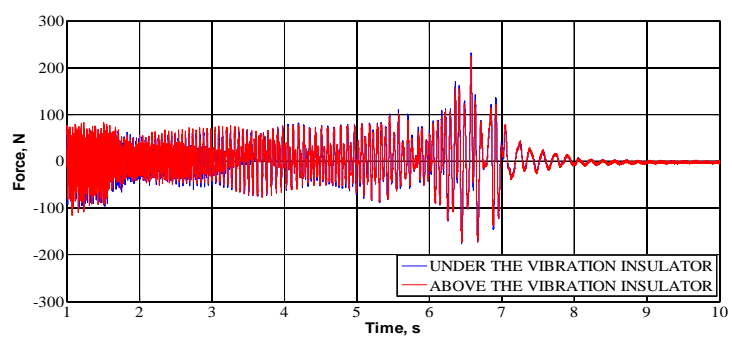

Chart -6: Forces above and under front right vibration insulator at stopping of the diesel generator 


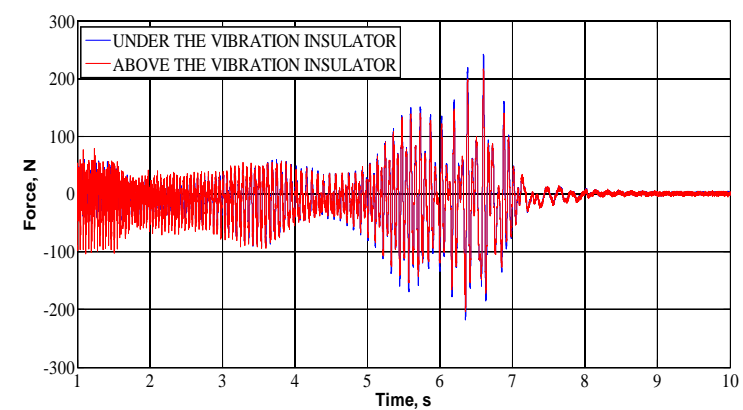

Chart -7: Forces above and under rear left vibration insulator at stopping of the diesel generator

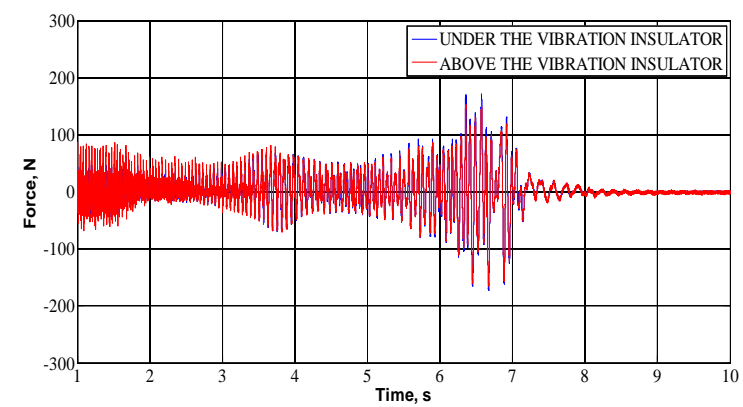

Chart -8: Forces above and under rear right vibration insulator at stopping of the diesel generator

By comparing the results obtained at the start and stop of a diesel generator, it may be noted that the amplitudes of the forces are larger at the start, and the duration of the transitional process is greater at stop.

The results of the measurements of the forces above and under the four vibration insulators of the diesel unit at full loading and unloading, are presented graphically in Chart 9, 10,11 and 12.

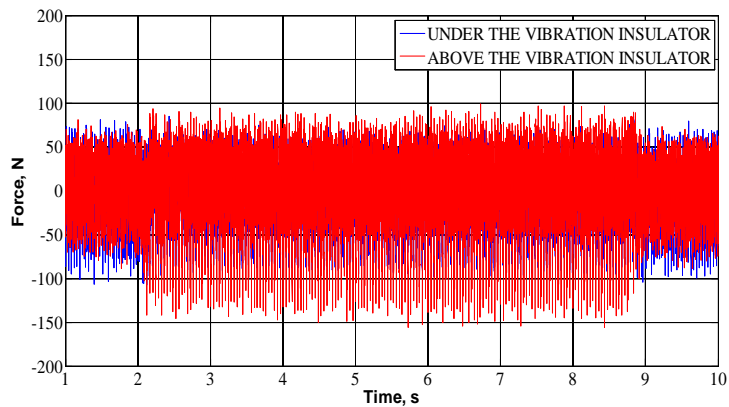

Chart -9: Forces above and under front left vibration insulator at full loading and unloading of the diesel generator

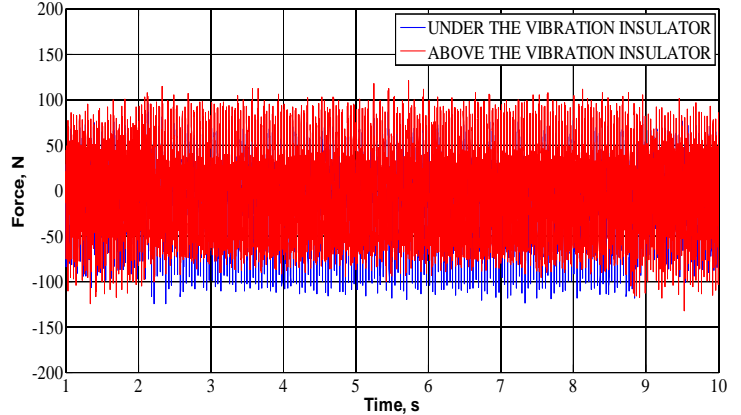

Chart -10: Forces above and under front right vibration insulator at full loading and unloading of the diesel generator

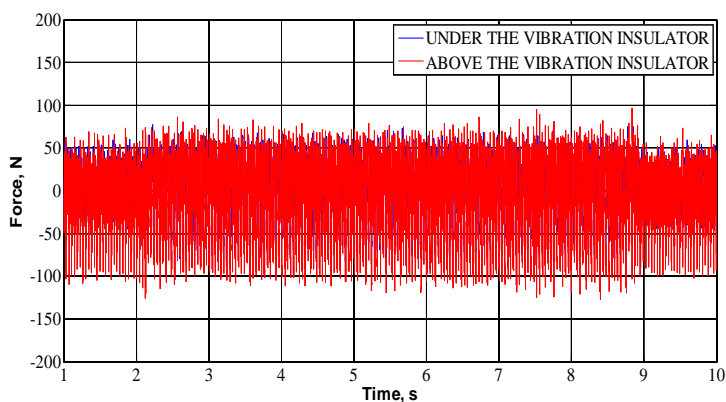

Chart -11: Forces above and under rear left vibration insulator at full loading and unloading of the diesel generator

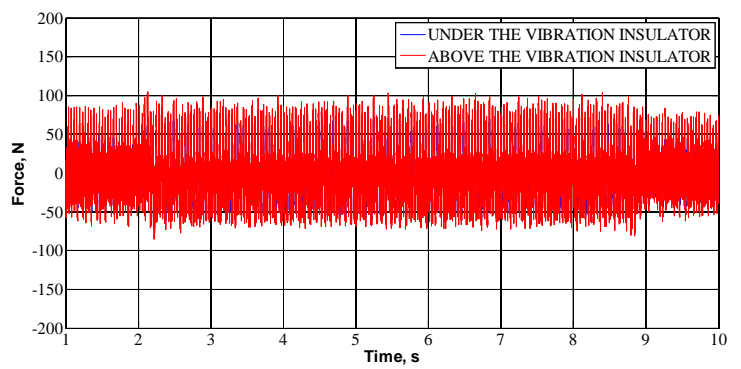

Chart -12: Forces above and under rear right vibration insulator at full loading and unloading of the diesel generator

By comparing the results obtained at the loading and unloading of a diesel generator with electric load, it may be noted that the amplitudes of the forces are increasing at loading, which is due to the large amounts of gas force and anti-torque under greater amount of heat emitted during the combustion process in the diesel engine.

The results of the measurements of the forces above and under the four vibration insulators of the diesel unit at full loading per one working cycle, as a function of the angle of rotation of the crankshaft, are presented graphically in Chart 13, 14, 15 and 16. 


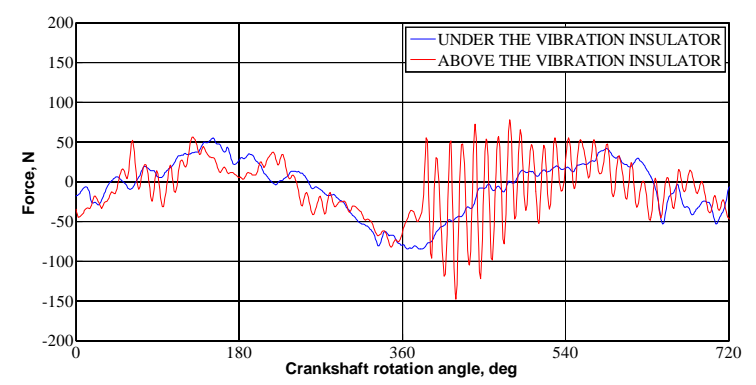

Chart -13: Forces above and under front left vibration insulator at full loading per one working cycle of the diesel generator

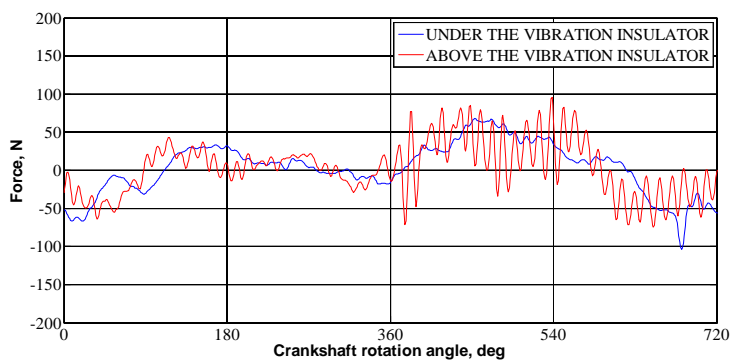

Chart -14: Forces above and under front right vibration insulator at full loading per one working cycle of the diesel generator

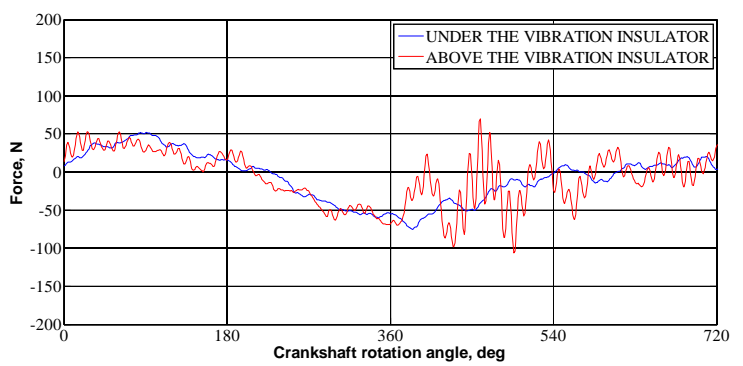

Chart -15: Forces above and under rear left vibration insulator at full loading per one working cycle of the diesel generator

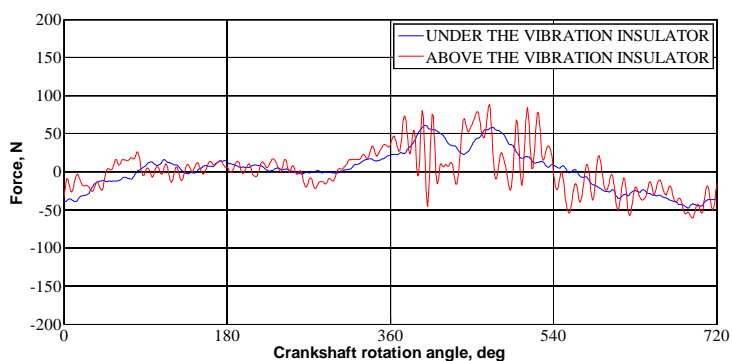

Chart -16: Forces above and under rear right vibration insulator at full loading per one working cycle of the diesel generator
The results of the measurements of the forces above and under the four vibration insulators of the diesel unit at idle running without external electrical load per one working cycle, as a function of the angle of rotation of the crankshaft, are presented graphically in Chart 17, 18, 19 and 20.

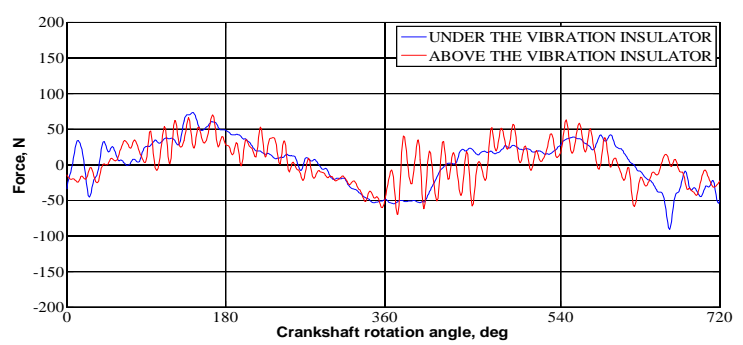

Chart -17: Forces above and under front left vibration insulator without load per one working cycle of the diesel engine

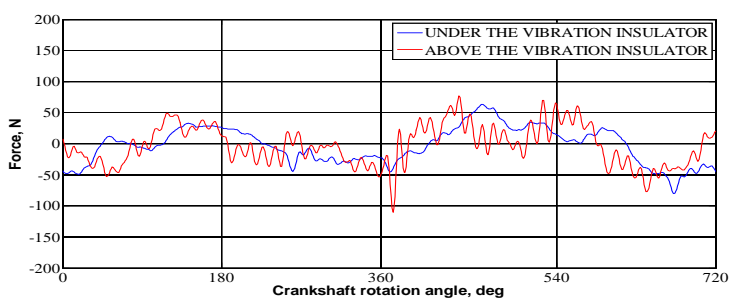

Chart -18: Forces above and under front right vibration insulator without load per one working cycle of the diesel engine

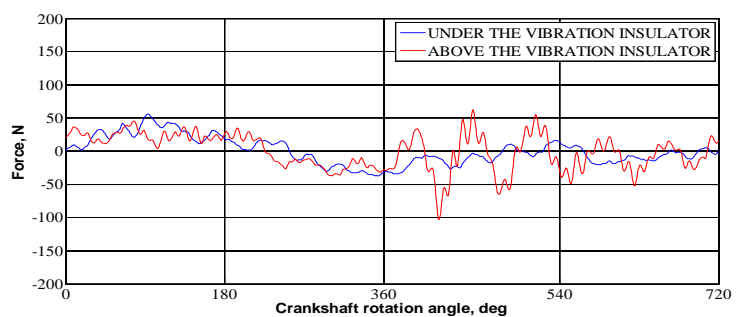

Chart -19: Forces above and under rear left vibration insulator without load per one working cycle of the diesel engine

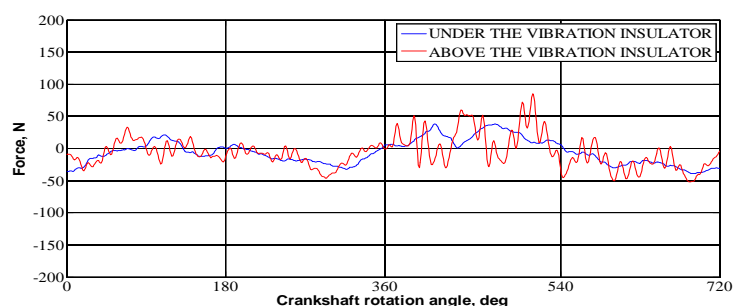

Chart -20: Forces above and under rear right vibration insulator without load per one working cycle of the diesel engine 
Comparing the results of measurements of the forces above and under the four vibration insulators of a diesel unit per operating cycle, as a function of the angle of rotation of the crankshaft at full load (Chart 13,.., 16) and at idle running (Chart 17, ..., 20), are observed significantly larger amplitudes of high-frequency components of the forces over the vibration insulators in direct proportion to the amount of heat emitted during the combustion process in the diesel engine.

\section{CONCLUSIONS}

A system is created for measuring the forces above and under the vibration insulators of a unit with single-cylinder fourstroke diesel engine and electric generator. A methodology is created for experimental study of the reactions in the supports above and under the elastic suspension elements of the unit, whereat the data for the measured values are stored, processed and visualized in a MATLAB environment. Here are presented and analyzed the results of the measurements of the forces above and under the four vibration insulators of the unit, as a function of time in transitional modes of the diesel generator: starting, stopping, loading and unloading with electric load.

Presented and analyzed are the results of the measurements of the forces above and under the four vibration insulators of the unit and of the diesel engine per working cycle, as a function of the angle of rotation of the crankshaft at its full load (maximum electrical load) and at idle running (without electrical load).

With the thus created measurement system and methodology a scientific and applied researches can be carried out, in order to determine the quality of the vibration insulation of machine units with internal combustion engines.

\section{REFERENCES}

[1]. Ambarev K., Nikolov V., Dimitrov E., Panchev S., Tashev A. System for experimental study of diesel engine. Scientific journal "Mechanics of Machines", Technical university of Varna, Bulgaria, 2014, Year XXII, Book 2, Issue 106, pp. 8-12.

[2]. Ambarev K., Nikolov V., Dimitrov P., Dimitrov E. Study of the influence of the compression ratio on the processes in the diesel engine. Scientific conference on Aeronautics, Automotive and Railway Engineering and Technologies "BulTrans-2013", 16-18.10.2013, Sofia, Technical university of Sofia, Bulgaria, Proceedings, pp. 31-35

[3]. Dimitrov P. Guide for laboratory experiments on theory of ICE. Technical university of Sofia, Bulgaria, 1999

[4]. Dimitrov P. Theory of ICE. Technical university of Sofia, Bulgaria, 2000

[5]. Nikolov V., Ambarev K. Study of the influence of the compression ratio of four stroke diesel engine. International virtual journal for science, technics and innovations for industry "Machines, Technologies and Materials", Scientific technical union of Mechanical engineering, Sofia, Bulgaria, Year VI, Issue 7, 2012, pp. 3-6.

[6]. Nikolov V., Ambarev K. Measuring system of the forces over and under the vibration insulator of diesel generator. Bulgarian journal for engineering design, Technical university of Sofia, Bulgaria, Issue 20, October 2013, pp. 35-41.

[7]. www.kipor.com

[8]. www.mathworks.com

[9]. www.mikas-service.ru

[10]. www.ni.com

[11]. www.zemic.nl

\section{BIOGRAPHIES}

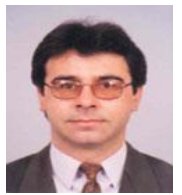

Assoc. prof. Valyo Nikolov, $\mathrm{PhD}$ is lecturer in Internal Combustion Engines (ICE) and has professional experience and interests in the field of ICE, Dynamics and Vibrations of Machines.

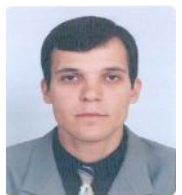

Assist. prof. Krasimir Ambarev is lecturer in ICE and has professional experience and interests in a field of ICE, simulation of the processes in ICE. 